\title{
O direito sindical como esfera do reconhecimento
}

\author{
Trade union law as a field of recognition \\ Marcos Paulo da Silva Oliveira \\ Pontifícia Universidade Católica de Minas Gerais
}

\begin{abstract}
Resumo O presente artigo se debruça sobre a nova realidade do movimento sindical brasileiro em contraposição ao iminente e perigoso discurso da flexibilização da ciência justrabalhista. Dá-se enfoque ao Direito Coletivo do Trabalho, tendo-se como pano de fundo a teoria do reconhecimento de Axel Honneth, pela qual se aponta o reconhecimento sindical como o mote capaz de balizar o enfrentamento da flexibilização e, mais, contribuir para a efetividade das negociações coletivas de caráter transacional e democráticas, afastando-se da mera renúncia de direitos, sobretudo diante do Capital Globalizado.
\end{abstract}

Palavras-chave: Reconhecimento. Direito Sindical. FlexibilizaÇão TRABALHISTA.

Abstract This article deals with the new reality of the Brazilian trade union movement in opposition to the imminent and dangerous discourse of the flexibilization of Labor Law. Focus is given to Labor Law, with the background of Axel Honneth's theory of recognition, which points out there cognition of trade union as the mote capable of balancing flexibilization and more, contribute to the effectiveness of negotiations Collective, transactional and democratic, moving away from the mere renunciation of rights, especially in the face of the Globalized Capital. Key-words: Recognition. Trade Union Rights. Flexibility of Labour LAW. 


\section{INTRODUÇÃo}

De maneira particularizada, apesar de a Constituição Federal de 1988 alçar os direitos sociais ao patamar de direitos fundamentais e, portanto, integrantes da dignidade humana, a própria Carta Magna apresenta dispositivos passivos de flexibilização pela negociação coletiva, ao passo que mantém a unicidade sindical, impedindo que haja a livre concorrência entre sindicatos obreiros.

Conforme adianta Túlio de Oliveira Massoni (2007), é possível dizer que a situação permanece bastante próxima do corporativismo ${ }^{1}$ inaugurado pela era Vargas, e é essa situação que paulatinamente nos parece colocar em xeque a representatividade dos sindicatos obreiros e acaba por favorecer o aparecimento de cláusulas prejudiciais aos trabalhadores nas negociações coletivas, principalmente com a difusão dos ideais flexibilizadores das garantias trabalhistas.

Neste estudo, busca-se analisar o reconhecimento sindical no Brasil contemporâneo, tendo como pano de fundo a iminente e perigosa possibilidade da desregulamentação ou simplesmente flexibilização do Direito do Trabalho.

Na flexibilização trabalhista, as necessidades do capital têm buscado a derrogação de garantias preexistentes ou sua substituição por outras inferiores alegando a manutenção do emprego, ao passo que tudo isso parece potencializado por uma ausência de reconhecimento intersubjetivo dos trabalhadores, que não mais se reconhecem entre seus pares, mas ao contrário, têm cada vez mais se identificado na figura do empregador e esvaziado os sindicatos obreiros (TEODORO, 2015). Segundo Oscar Ermida Uriarte (2002), esse movimento corrobora com a privação de direitos fundamentais dos sujeitos obreiros e por isso deve ser combatido.

\footnotetext{
1 No presente estudo não se pretende esgotar as polêmicas acerca das críticas ao corporativismo da Era Vargas, mas apresentar a posição jurídico-doutrinária de que esse modelo fez arrefecer o movimento sindical, impedindo que ele desenvolvesse a sua potência revolucionária. Sobre o tema, recomendamos a leitura de: SOUTO MAIOR, Jorge Luiz. História do direito do trabalho no Brasil: curso de direito do trabalho, volume: I: parte II. São Paulo: LTr, 2017.
} 


\section{O TRABALHO NO NOVO PARADIGMA CONSTITUCIONAL E OS Sindicatos na Constituição da República de 1988}

Rompendo com o modelo ditatorial e com boa parte do ordenamento jurídico anterior, o preâmbulo da Constituição da República Federativa do Brasil de 1988 institui no ordenamento jurídico brasileiro o paradigma do Estado Democrático de Direito. A nova ordem constitucional representa um marco jurídico da transição democrática, da ampla participação popular e da institucionalização dos direitos fundamentais, haja vista que inaugurou na ordem jurídica brasileira um título específico destinado a esses direitos, e que lhes garante qualidade de normas basilares (CANOTILHO, 2000).

A Constituição de 1988 marca a transição do período ditatorial para um processo de democratização, em que a ampla participação popular se faz o cerne da vida política (SARLET, 2009). Aqui é possível verificar a importância do reconhecimento sindical como forma de ampliar essa participação popular nas decisões políticas do país.

Aponta-se então que os direitos fundamentais (incluindo-se os direitos fundamentais do trabalho) seriam a limitação e o controle dos abusos do próprio Estado, devendo aqueles ser examinados sempre sob a ótica da dignidade humana, pois a dignidade da pessoa humana se configura não somente como princípio fundamental, mas também como valor supremo, devendo estar livre de restrições, sendo desproporcionais e incabíveis quaisquer soluções que respaldem o tratamento indigno, sejam elas extraídas a partir de colisão entre princípios ou de conflito entre regras que envolvam um direito fundamental (SARLET, 2009).

Com relação ao direito coletivo do trabalho, e mais especificamente sobre os sindicatos, a Constituição da República apresenta alguns avanços, os quais em determinados momentos se mostram contrários a institutos que ela mesma implementa ao longo de seu texto.

Conforme as lições de Tulio de Oliveira Massoni, aparentemente os sindicatos conquistaram autonomia, contudo, os trabalhadores não conquistaram sua liberdade de organização, existem restrições com relação à base territorial e os sindicatos precisam ser reconhecidos pelo Poder Público. 
“A Constituição da República do Brasil de 1988 (art. 8., I) vedou a intervenção e a interferência do Estado na organização sindical, mas manteve (art. $8^{\circ}$., II) a unicidade sindical" (MASSONI, 2007, p. 160).

A situação permanece bastante próxima do corporativismo inaugurado pela era Vargas, e é essa situação, como veremos em breve, que parece trazer à tona uma crescente falta de representatividade e o aparecimento de cláusulas "in pejus" - prejudiciais aos trabalhadores - nas negociações coletivas, principalmente com a difusão dos ideais flexibilizadores das garantias trabalhistas.

Neste trabalho, entende-se como mais adequado o posicionamento de que a liberdade e a unicidade são incompatíveis entre si, sendo claro que a restrição territorial imposta aos sindicatos não lhes dá autonomia e liberdade, ao contrário, acaba tolhendo qualquer perspectiva de livre concorrência entre entes coletivos obreiros, que em outra situação (liberdade e pluralidade) poderiam competir por uma maior garantia de direitos aos trabalhadores sindicalizados.

\section{O ENFRAQUECIMENTO DOS SINDICATOS OBREIROS E AS NEGOCIA- ÇÕES COLETIVAS QUE DENUNCIAM RENÚNCIAS DE DIREITOS}

No Brasil, atualmente experimenta-se verdadeiro momento de difusão do discurso flexibilizador e partindo da aparente fraqueza sindical no Brasil contemporâneo e das fervorosas tentativas do mercado em combater o desemprego estrutural, rompendo com a lógica protetiva do Direito do Trabalho, tem-se encontrado nas negociações coletivas, por contraditório que seja, dispositivos que corroboram com atos antissindicais.

Esses atos tendem a produzir verdadeira descentralização e até individualização da negociação. Assim, muitas vezes aparecem cláusulas "in pejus" nas convenções e acordos coletivos, que mitigam os direitos dos trabalhadores e claramente violam a finalidade protetora do Direito Laboral.

Com certa frequência, tem se visto cláusulas prejudiciais aos trabalhadores nos instrumentos coletivos. Tais cláusulas por vezes têm os limites transacionais respeitados, mas por vezes violam disposições le- 
gais e constitucionais e fazem saltar aos olhos a tônica da flexibilização promovida com o auxílio dos sindicatos obreiros, que chancelam negociações coletivas que renunciam a direitos trabalhistas outrora conquistados por meio de lutas históricas.

Quando de cláusulas manifestamente ilegais ou inconstitucionais, não eventualmente o poder judiciário é chamado a intervir, promovendo a anulação de cláusulas em convenções e acordos coletivos. Orientações Jurisprudenciais e Súmulas do Tribunal Superior do Trabalho também se fazem uma constante, visando o não aparecimento de cláusulas "in pejus" nas negociações coletivas brasileiras.

Cabe citar, ilustrativamente, a ação anulatória proposta pelo Ministério Público do Trabalho (autos $\mathrm{n}^{\mathrm{o}}$. 00003-2012-000-10-00-0), com o objetivo de obter a declaração de nulidade de cláusula convencional ajustada entre o Sindicato dos Garçons e Empregados em Hotéis, Bares, Restaurantes e Similares do Estado de Tocantins e o Sindicato do Turismo e Hospitalidade do Estado do Tocantins.

O Ministério Público do Trabalho sustentou que a cláusula 14 da Convenção Coletiva em questão, em contrariedade à norma do artigo $457, \S 3^{\circ}$., da CLT, dispõe que "Os estabelecimentos que cobrarem de seus clientes taxa de serviço pagarão aos garçons $6 \%$ (seis por cento), acrescido do salário base da categoria".

Acertadamente, declarada pelo Tribunal Regional do Trabalho da $10^{\mathrm{a}}$ Região a nulidade da cláusula, posto que dispõe de maneira contrária a garantia trabalhista conferida por lei, descumprindo, portanto, um dos preceitos básicos para que possa haver transação de direitos por meio de negociação coletiva (BRASIL, 2012). É o que alerta Maria Cecília Máximo Teodoro (2007) ao indicar a necessidade em entender os limites a serem impostos a tais negociações, por meio do princípio da adequação setorial negociada.

Adiantado o atual momento de negociações coletivas que não coadunam com os princípios protetores do Direito do Trabalho, nota-se no Brasil contemporâneo a disseminação de verdadeiro discurso em prol do enfraquecimento sindical e de propostas de flexibilização das leis laborais, com a justificativa de sanar as cíclicas crises econômicas. 
Nesse sentido, pode-se citar o $\S 3^{\circ}$. do artigo $8^{\circ}$. da CLT, com redação dada pela Lei 13.467/2017, que aparentemente tenta limitar a esfera de atuação do Poder Judiciário no tocante à análise das negociações coletivas. Essa legislação em alguma medida também expressa a difusão da flexibilidade nas relações de trabalho brasileira.

$\mathrm{Na}$ flexibilização trabalhista, as necessidades do capital têm buscado a derrogação de garantias preexistentes ou sua substituição por outras inferiores, alegando a manutenção do emprego. Nesse movimento, há vasta privação de direitos fundamentais dos sujeitos obreiros. A flexibilização promove exclusões, que não são toleradas em uma sociedade democrática.

O discurso flexibilizador e a ausência de representação sindical são temas dos mais importantes e controvertidos na ciência jurídica contemporânea, afinal colocam em xeque todo o modelo sindical construído e mantido no Brasil nas últimas décadas. É preciso apontar novas direções para as questões sindicais, é ainda, preciso entender a necessidade do sujeito se reconhecer como trabalhador e junto aos seus pares militar pelos direitos inerentes à sua classe, bem como por uma experiência de vida mais digna e qualificada.

\section{A FleXibilizaÇão do trabalho E OS EFEITOS DO NEOLIBERA- LISMO NAS RELAÇÕES DE EMPREGO}

A flexibilidade trabalhista pode ser definida como mitigação ou eliminação da clássica proteção trabalhista, com o fim de aumentar o investimento, o emprego ou a competitividade empresarial. Essa flexibilização trabalhista passa a ser um fenômeno recorrente no contexto de crises econômicas (URIARTE, 2002).

Os empregadores brasileiros aderiram ao modelo de produção toyotista, na medida em que passaram a "racionalizar espaços, custos e a diminuir o quadro de empregados, além de efetivar uma maciça terceirização" (TEODORO, 2007, p. 48). Soma-se a isso a nova postura adotada pelo país visando atrair investimentos do capital estrangeiro, para isso, passando a tomar medidas como "a redução de impostos para 
o capital externo, a precarização do labor, o avanço da terceirização e a flexibilização das leis trabalhistas" (TEODORO, 2007, p. 50).

No Brasil, nas últimas décadas, tem se visto um processo de surgimento de formas alternativas de contratação laboral "todas elas, não por coincidência, assegurando um patamar civilizatório muito mais acanhado do que aquele garantido pelo Direito do Trabalho" (DELGADO, 2005, p. 134). Nesse sentido, Maurício Godinho Delgado (2005) ainda comenta que tem sido um fator determinante a corroborar com a flexibilização do mercado de trabalho a resistência na difusão do Direito do Trabalho como modelo orientador da contratação de mão de obra na sociedade e economia brasileira. O autor (DELGADO, 2005) ainda comenta que o Direito Laboral no Brasil já sofre naturalmente de flexibilização e desregulamentação, posto que atinge apenas uma pequena parcela da população.

Para Maria Cecília Máximo Teodoro (2007), até mesmo a Constituição da República de 1988, tida como uma constituição cidadã, reservou espaços para a flexibilização do Direito do Trabalho. O que, quando verificados os objetivos dirigentes apresentados pelo texto constitucional, assim como a valorização do trabalho que esta pretende, apresenta-se como algo bastante contraditório.

Para o professor Francisco Muñoz (2005, p. 235-238), a flexibilidade trabalhista se dá na adaptação do Direito do Trabalho às variações e flutuações do mercado. Essa flexibilização acontece principalmente por intermédio das contratações temporárias, difusões de dispensas imotivadas e redução da imperatividade das normas heterônomas, uma vez que seus opostos são considerados condições enrijecidas do Direito Laboral, o que atinge diretamente o cerne desta pesquisa.

Assim, Francisco Muñoz (2005) diferencia três tipos de flexibilidade do emprego: a flexibilidade neoliberal, a flexibilidade ancorada no liberalismo coletivo, e a flexibilidade de adaptação às crises. A flexibilidade neoliberal busca a desregulamentação do Direito do Trabalho, priorizando a negociação, em especial a individualizada. Nela, verifica-se a mitigação da incidência de normas heterônomas, de maneira que a legislação trabalhista passa a apenas apontar diretrizes, possibilitando 
que as condições juslaborais sejam definidas por meio da negociação individualizada, na qual se retira da parte obreira a sua capacidade coletiva de barganha.

Já a flexibilidade ancorada no liberalismo coletivo busca a desregulamentação do Direito do Trabalho, de maneira a conferir maiores autonomias negociais aos sindicatos. Nesse tipo de flexibilidade, torna-se comum (numa conjuntura de enfraquecimento sindical) que apareçam normas "in pejus" para a classe obreira, afinal o sindicato assume papel decisivo nas disposições sobre as condições de trabalho, e dependendo das características de atuação do organismo sindical, pode ceder mais facilmente aos interesses empresariais.

Por último, a flexibilidade de adaptação às crises busca a implementação de diversas medidas flexibilizadoras, ou que diminuam as garantias trabalhistas de acordo com as necessidades impostas pela conjuntura econômica.

\section{REPRESENTATIVIDADE E DIREITO SINDICAL}

No Brasil, tende-se a predominar a vertente heterônoma de norma trabalhista e no atual contexto de crises econômicas, vastas têm sido as tentativas de flexibilizar o Direito do Trabalho, enfraquecendo normas de proteção individual, primando-se pela negociação coletiva.

Contudo, esse movimento carece de análise cautelosa, uma vez percebido o atual enfraquecimento sindical, motivo pelo qual, nesse argumento se insere a flexibilidade incondicionada, isto é, renúncia gratuita de direitos por parte dos trabalhadores, na expectativa de manutenção do emprego. Não se verifica nesses casos qualquer representatividade do ente coletivo, não do ponto de vista trabalhista.

De acordo com Túlio de Oliveira Massoni (2007), a representatividade é primordial ao se tratar de sindicatos, sendo essa representatividade o indicador das perspectivas sindicais diante das crises. 
Nesse contexto, tem se inserido a chamada "síndrome de patrão", pela qual se verifica inclusive o fenômeno da "pejotização". Tratam-se de fenômenos pelos quais o trabalhador não mais se reconhece entre seus pares, enfraquecendo, sobretudo, o sentimento de pertencimento e a própria representatividade sindical (TEODORO, 2015).

Apesar de num primeiro momento não ter sido essa a intenção do legislador constituinte, nem ao menos da sociedade brasileira, no contexto de crises econômicas, em que se escancara o esgotamento do atual modelo de produções e consumo em massa, o capital se vê em condições práticas de retornar a um passado desprotetor (HAZAN, 2012).

Portanto, quando verificado o aparente contexto de fraqueza sindical no Brasil e as fervorosas tentativas do mercado em combater o desemprego estrutural, flexibilizando os direitos dos trabalhadores e rompendo com a lógica protetiva do Direito do Trabalho, tem-se, nas negociações coletivas, dispositivos que corroboram com atos antissindicalistas, produzindo verdadeira descentralização e até individualização da negociação.

Com frequência, aparecem cláusulas "in pejus" nas convenções e acordos coletivos, que mitigam os direitos dos trabalhadores e claramente violam a finalidade protetora do Direito Laboral. Por isso, oportuno salientar a perniciosidade de se "atribuir validade a toda e qualquer cláusula só porque ela é fruto de negociação coletiva, como se os sindicatos fossem detentores de uma espécie de carta branca das categorias que representam" (TEODORO, 2007, p. 97).

A flexibilidade incondicionada tem se mostrado prática recorrente na América Latina, ao passo que na Europa destaca-se a negociação bilateral pautada na composição, dadas as condições de igualdade entre os sindicatos dos trabalhadores e os sindicatos patronais (URIARTE, 2002).

Com a força do discurso do capital, o Direito do Trabalho passa a ser objeto de ampla disputa por parte dos empregadores e, paulatinamen-

2 TEODORO, Maria Cecília Máximo. A síndrome de patrão. Palestra proferida no IV Congresso Latino-americano de Direito Material e Processual do Trabalho. Punta Del Leste/Uruguai, dez. 2015. 
te, de toda a sociedade. Nesse momento, o próprio trabalhador passa a acreditar nesse discurso. Pensa-se que os direitos trabalhistas custam caro e são demasiados e, por isso, os causadores das crises que, em geral, se mostram fruto do capital especulativo. "Os próprios sindicatos passam a acreditar neste discurso, legitimando e permitindo a progressiva redução e flexibilização destes direitos" (HAZAN, 2012, p. 47).

Certamente, então, uma crise também se instaurou dentro do sindicalismo brasileiro. O enfraquecimento dos sindicatos vem junto com a quebra da solidariedade grupal (o trabalhador terceirizado se torna inimigo do trabalhador efetivado, este temendo por seu emprego e aquele ensejando o emprego do outro) e a diluição das categorias (realizando os mesmos serviços dentro da mesma fábrica há, agora, trabalhadores com categorias e direitos diferenciados) (HAZAN, 2012, p. 49).

Por isso, Maria Cecília Máximo Teodoro (2007) aponta a necessidade em entender os limites a serem impostos a tais negociações, considerando-se todo o processo de flexibilização e enfraquecimento dos sindicatos dos trabalhadores.

Surge desta discussão a necessidade em aprofundar estudos acerca da necessidade de um reconhecimento sindical, para que se enfrente o discurso flexibilizador e para que as crises econômicas (cíclicas) não retrocedam a ciência justrabalhista.

$\mathrm{Na}$ contemporaneidade, cada vez mais nos parece haver certa tendência social a dar preferências às questões individuais, o que, inclusive, justifica o descaso para com as demandas sindicais. Torna-se clara a necessidade de um reconhecimento emancipatório desses entes coletivos, que rompa com o modelo de individualização social. ${ }^{3}$

Para a consecução desse fim, acredita-se que, apesar de extremamente necessários, não bastam os marcos teóricos jurídicos, pois é preciso uma visão polifônica da problemática, já que o desrespeito aos

3 Sobre o tema, recomendamos a leitura da seguinte obra: BAUMAN, Zygmunt. Modernidade Líquida. Tradução: Plínio Dentzien. Rio de Janeiro: Jorge Zahar Ed., 2001. 
direitos trabalhistas não se dá apenas nas relações laborais, mas ocorrem também e principalmente questões políticas, próprias da manutenção de uma estrutura de dominação historicamente determinada.

As crises do sistema econômico vigente têm sido o principal argumento para o abrandamento do Direito do Trabalho. A desconstrução desses argumentos é medida que se impõe na atual era da flexibilidade. Afinal, o Direito do Trabalho nasce de crises, e mais, "ganha destaque com as crises, é combatido a cada crise que se apresenta, mais do que qualquer outro ramo do Direito sofre os efeitos das medidas adotadas para combater crises e dele é exigido que mostre a sua força especialmente em momentos de crise" (ALMEIDA, 2016, p. 41).

Portanto, o que se apronta é a necessidade de que o Direito do Trabalho brasileiro e os próprios sindicatos obreiros se efetivem como instrumentos de transformação social, pautados na justiça social e vida digna de seus destinatários, tudo isso, sob pena do desaparecimento de suas razões de ser e de seu desaparecimento.

\section{A teoria do reconhecimento de Axel Honneth no DIREITO COLETIVO DO TRABALHO}

Sob o prisma da teoria do reconhecimento recíproco remontada por Axel Honneth, tem-se a necessidade em rediscutir a representatividade sindical diante do iminente discurso da flexibilização. Conforme explana esse autor, "os sujeitos só podem chegar a uma auto-relação prática quando aprendem a se conceber, da perspectiva normativa de seus parceiros de interação, como seus destinatários sociais" (HONNETH, 2003, p. 155).

As interseções entre o reconhecimento e a representatividade são latentes, posto que o sentimento de pertencimento e o próprio reconhecimento de classe é imprescindível para um sindicato forte e combativo.

Nos ensinamentos de Axel Honneth (2003), temos que um sujeito não se compõe apenas pelos direitos que possui, mas por todas as relações jurídicas, afetivas e sociais das quais é parte, sendo necessária uma concepção ampliada do ser humano. 
Pelo que se tem da tradição sociológica adotada pelo referido autor (HONNETH, 2003), a teoria do reconhecimento nos indica um caminho de interpretação crítica dos processos de evolução social, em que se aproxime o estado último de um conceito expansivo de moral, que se afaste de perspectivas estreitas.

Na obra do autor (HONNETH, 2003), para o estudo das lutas sociais temos indicados conceitos de identidade, reconhecimento, direitos e deveres, todos convergindo para um estudo sobre a dignidade dos sujeitos e para a consolidação de um conceito do que ele chama de "eticidade".

Cumpre destacar certas divergências surgidas ao longo do tempo no tocante à teoria do reconhecimento recíproco remontada por Axel Honneth (2003). No estudo conjunto intitulado Redistribution or Recognition? A Political-Philosophical Exchange (2006), são feitas algumas observações à obra de Axel Honneth (2003), sobretudo quanto à preferência de sua teoria pelas categorias éticas em detrimento de categorias mais políticas e econômicas. É o que se extrai dos dizeres de Nancy Fraser (2006), quando na referida obra dispõe que apesar das grandes comunhões, ela e Honneth discordam sobre a forma de alcançar o mesmo objetivo comum.

A estratégia de Honneth para o abrigo da imanência e transcendência parte da Teoria Crítica pela psicologia moral do sofrimento pré-político. Para identificar a imanência com a experiência subjetiva, ele propõe uma conexão crítica com seu contexto social, derivando seus conceitos normativos dos sofrimentos, motivações e expectativas dos sujeitos sociais. Esta estratégia é arriscada, e ameaça entrar em colapso normativo pelo que é dado. Para evitar este perigo, Honneth resolve tomar distância das disputas políticas atuais (HONNETH; FRASER, 2006, p. 202, tradução livre dos autores). ${ }^{4}$

\footnotetext{
4 His strategy for accommodating immanence and transcendence is to ground Critical Theory in a moral psychology of prepolitical suffering. Identifying immanence with subjective experience, he proposes to connectcritique with its social context by deriving its normative concepts from the suffrelings, motivations, and expectations of social subjects. This strategy is risky, however, as it threatens to collapse normativity into the given. To forestall this danger, Honneth resolves to take distance from the political disputes of the present (HONNETH; FRASER, 2006, p. 202).
} 
Tais críticas não nos parecem inviabilizar a abordagem aqui pretendida, ao contrário, se incorporam ao próprio objeto de estudo e chegam a oportunizar o teste da hipótese.

Para a análise dessas lutas históricas por reconhecimento, é preciso ainda antecipar um estado último preliminar, para que possamos classificar e avaliar os fenômenos sociais de maneira particularizada. Esse estado último, para os sindicatos no Brasil é o da unicidade, bem como, a disseminação do discurso da flexibilização do trabalho.

A partir disso é então desenhado o conceito de "eticidade" pelas três diferentes dimensões de reconhecimento, são elas: reconhecimento no campo privado (amor), nas relações jurídicas (direito), e na esfera social (solidariedade).

Assim, é necessário adentrar em tais questões para que se possa entender como essas condições teóricas podem auxiliar na construção prática de um modelo sindical em que os trabalhadores tenham seus direitos assegurados e efetivados.

\section{Direito SINDiCAL E RECONHECIMENTO: DiÁlogos POSSÍVEIS}

Para o reconhecimento sindical que se deseja apontar neste estudo, será utilizado o conceito de "eticidade" abordado na obra de Axel Honneth (2003). Assim, serão apontados três momentos muito específicos para o reconhecimento.

No campo privado, a fase inicial refere-se ao amor. Axel Honneth alerta que, ao se tratar do amor, "recomenda-se primeiramente um modo de emprego neutro o máximo possível: por relações amorosas devem ser entendidas aqui todas as relações primárias, na medida em que elas consistam em ligações emotivas fortes entre poucas pessoas" (HONNETH, 2003, p. 159).

Nessa fase inicial, o sujeito e o outro sujeito se encontram em uma relação simbiótica, em que ainda não há limite de individualidade, há apenas uma unidade que comporta os dois sujeitos, por isso Axel Honneth lança mão do exemplo da mãe gestante e do bebê. 
Com um processo de relativa independência dessas pessoas surge a autoconfiança, no caso, quando o bebê já concebido começa a experimentar uma confiança no outro, além de um amor recíproco, que se torna elemento essencial para o reconhecimento jurídico. A autoconfiança é a base para todas as relações entre as pessoas adultas e ela só pode ser conquistada por meio de uma experiência recíproca de amor e respeito com o outro.

O autor ainda sustenta que o nível do reconhecimento do amor é o núcleo fundamental. Sendo assim, é responsável não só pela base de autorrespeito, mas também para a participação na vida pública.

Para os sindicatos, é possível entender que o elemento do amor está no autorreconhecimento de classe, em que os obreiros reconhecem seus pares e passam a militar por ideais coletivos, entendendo que o benefício em classe é mais importante do que o benefício individual.

Nessa primeira experiência é que se forma o associativismo, encontra-se a liderança (dirigentes sindicais) e se experimenta uma organização capaz de encabeçar a luta por reconhecimento. Se esse momento é violado por conflitos internos e/ou externos, não se tem uma associação de trabalhadores fortemente capaz de lutar pelo avanço em seus direitos no momento da negociação.

Assim, se o momento é violado, os trabalhadores deixam de experimentar a confiança recíproca e a autoconfiança para vivenciar o que Axel Honneth chama de lesões psíquicas, ou experiências de desrespeito.

Para Honneth (2003), cada fase de construção do conceito de "eticidade" possui formas contrárias correspondentes. No caso do amor, os contrários correspondentes são os maus-tratos e a violação. Nessa forma de desrespeito, o componente da personalidade que é atacado é a integridade psíquica, ou o autorrespeito que cada pessoa possui de seu corpo (HONNETH, 2003).

Para os sindicatos, essa violação pode ser verificada no fenômeno já comentado neste estudo, isto é, a "síndrome de patrão", em que os trabalhadores não se reconhecem como tal, ao contrário, se idealizam enquanto empregadores e passam até mesmo a se tornar pessoas jurídicas, apesar de ainda subordinados estruturalmente ao antigo empregador (TEODORO, 2015). 
Se vivenciada de maneira adequada, a partir da primeira dimensão de reconhecimento (amor) temos as condições para o surgimento do segundo nível de reconhecimento, isto é, o direito.

Para Axel Honneth (2003), o reconhecimento no nível do direito deve ser reconstruído como forma de ampliar os direitos fundamentais.

Pode-se verificar aqui a necessidade em reformular a estrutura sindical diante da legislação vigente que de maneira contraditória afirma que os sindicatos são livres apesar de únicos, e agora, a partir da Lei 13.467/2017 retira a contribuição sindical obrigatória.

Como já visto, em regime de unicidade sindical não há espaço para se discutir a noção de representatividade, conceito vinculado a sistemas democráticos que prestigiam a liberdade sindical em todas as suas dimensões.

Se experimentada a pluralidade sindical, em que na livre concorrência prevaleça o sindicato obreiro mais benéfico à classe, teremos condições para a ampliação das negociações coletivas, a exemplo do que acontece em outros lugares do mundo.

Sobre a importância do princípio da liberdade sindical, necessário se faz trazer à tona os dizeres do Pacto Internacional sobre Direitos Econômicos e Culturais (BRASIL, 1992), adotado pela XXI Sessão da Assembleia-Geral das Nações Unidas, em 19 de dezembro de 1966, o qual dispõe em seu artigo $8^{\circ}$., o compromisso dos Estados em garantir o direito de liberdade sindical. Esse Pacto, de acordo com o Decreto ${ }^{\circ}$. 591, de 6 de julho de 1992, será inteiramente adotado pelo Brasil, contudo, como vimos brevemente, a Constituição da República Federativa do Brasil de 1988 adere ao modelo sindical da unicidade.

A negociação coletiva, quando já estabelecido o respeito à dignidade humana e o empoderamento dos sindicatos obreiros por meio da liberdade sindical e do fortalecimento em classe, poderá fazer largo uso da flexibilização positiva, isto é, de normas coletivas globalmente mais benéficas aos obreiros.

Existem mínimos existenciais que não podem ser renunciados, seja por meio de negociação ou mesmo por atuação legislativa.

Os direitos sociais do trabalho esculpidos na Constituição Federal de 1988 representam esse mínimo existencial, sendo um componente 
importante do princípio da dignidade humana, que, por sua vez, é o núcleo central dos direitos humanos.

Se o reconhecimento jurídico é debilitado ou defeituoso (como atualmente o é), seja por meio da dominação patronal (ausência de estabilidade no emprego, ausência da pluralidade sindical), seja por meio de um Direito do Trabalho não protetivo (o que por si só já seria um contrassenso) temos balizada uma privação de direitos, e o pior, privação de direitos fundamentais.

Assim, o contrário correspondente do nível de reconhecimento do Direito passa a ser a privação de direitos e, nessa esfera do reconhecimento, o componente da personalidade que é ameaçado é aquele da integridade social.

Finalmente, a solidariedade é a terceira dimensão de reconhecimento, e pelo autor é tida como "um meio social pelo qual as propriedades diferenciais dos seres humanos venham à tona de forma genérica, vinculativa e intersubjetiva" (HONNETH, 2003, p. 199).

Aqui se fala principalmente de honra e da própria dignidade humana. A honra está principalmente atrelada à percepção social e à estima coletiva para com os sujeitos.

Nas sociedades modernas, "as relações de estima social estão sujeitas a uma luta permanente na qual os diversos grupos procuram elevar, com os meios da força simbólica e em referência às finalidades gerais, o valor das capacidades associadas à sua forma de vida" (HONNETH, 2003, p. 207).

O contrário correspondente ao nível da solidariedade é o desrespeito da degradação moral e a injúria, sendo que a dignidade humana e a honra é que se encontram ameaçadas, pois o indivíduo não consegue desenvolver uma boa estima de si mesmo.

Destaca-se a percepção social como forte instrumento de luta e o grande diferencial para a efetivação do reconhecimento por meio da solidariedade.

Entretanto, atualmente os sindicatos encontram dificuldades em externar suas pautas para as grandes mídias e para sensibilizarem o corpo social da importância da efetivação de seus direitos constitucionais 
e infraconstitucionais. Muito se culpa, nesse sentido, a aparente cooptação das centrais sindicais por parte de partidos políticos.

$\mathrm{Na}$ visão midiática, muitas vezes a greve é tida como um mal e não mais como um instrumento de luta constitucionalmente previsto aos trabalhadores.

O próprio sindicato, nessa medida, aparece por vezes como um "vilão", já que permeia na sociedade algum sentimento de que o Direito do Trabalho é demasiadamente protetor, o que ao longo deste trabalho esperamos ter desconstruído.

Assim, nos adianta Honneth:

[...] o que decide sobre o desfecho dessas lutas, estabilizado apenas temporariamente, não é apenas o poder de dispor dos meios da força simbólica, específico de determinados grupos, mas também o clima, dificilmente influenciável das atenções públicas: quanto mais os movimentos sociais conseguem chamar a atenção da esfera pública para a importância negligenciada das propriedades e das capacidades representadas por eles de modo coletivo, tanto mais existe para eles a possibilidade de elevar na sociedade o valor social ou mais precisamente, a reputação de seus membros (HONNETH, 2003, p. 207-208).

Os papéis da organização coletiva e da pressão popular se avultam, uma vez que sem esses instrumentos a marginalização das lutas sindicais se mostra latente, é preciso o reconhecimento e empoderamento desses coletivos para que possam negociar com paridade de armas junto aos sindicatos patronais, mas não só isso.

O sindicato hoje já não mais pode contar com o apoio do Estado, que é um dos grandes promotores da flexibilização, paulatinamente, o sindicato vem deixando também de contar com o apoio dos próprios trabalhadores. Importante então destacar que é preciso ir além da simples consciência de classe pela busca patrimonial e instrumentalista, é preciso que o trabalhador volte a se reconhecer no coletivo e se sinta 
pertencente e representado pelo sindicato. Esse é o grande desafio do sindicalismo contemporâneo, reconquistar o seu principal destinatário.

\section{Considerações Finais}

Partindo do problema em torno do Direito Sindical como esfera do reconhecimento, os sindicatos passam a ser vistos como instrumentos de efetivação dos direitos constitucionais previstos aos trabalhadores e aos cidadãos brasileiros.

É preciso redescobrir a consciência de classe dos obreiros, ao passo que esta não deve apenas se pautar por questões econômicas, mas deve pleitear, sobretudo, a melhoria da vida digna dos trabalhadores.

Avulta-se a importância no momento atual em garantir novas proteções aos trabalhadores, tanto em âmbito coletivo quanto individual, inclusive das ações do próprio Estado, verificadas as tendências flexibilizadoras que este tem adotado nos últimos anos.

A primeira proteção deve ser a de assegurar os direitos sociais já conquistados, evitando-se o retrocesso dos direitos fundamentais. Progressivamente, é preciso buscar o reconhecimento mútuo entre trabalhadores, empregadores, Estado e sociedade civil organizada, para que conjuntamente se perceba a importância da articulação do trabalho e capital em nível de garantir uma experiência de vida digna e qualificada aos cidadãos.

A organização coletiva e a percepção social são desafios que precisam ser enfrentados, já que têm importante papel no combate ao desrespeito e degradação moral dos sujeitos obreiros, até mesmo balizando a efetivação e o desenvolvimento de todos os níveis de reconhecimento. Inclusive o reconhecimento do próprio Direito do Trabalho.

É preciso repensar a legislação sindical, ao passo que garantir a pluralidade nos parece questão de suma importância, afinal, diante da concorrência os sindicatos não mais arrefecerão sua combatividade, passando a sempre primar pelo melhor interesse dos empregados que representam.

Necessário se faz readequar o sistema sindical brasileiro no intuito de garantir maior autonomia, representatividade e equiparação de 
forças daquele em relação ao capital, para que num futuro próximo a participação dessa entidade coletiva possa gerar maiores direitos aos trabalhadores e não derrogar garantias a troco de nada. Superada a fragilidade sindical, a ampliação da negociação coletiva se tornará uma realidade, já que dentro de um limite politicamente aceitável promoverá a nível setorial uma gama de direitos maior para os empregados, que participando ativamente da dinâmica empresarial, possivelmente trarão melhores resultados para o empregador.

Quando desse momento, superar crises sem a mitigação dos direitos dos trabalhadores não parecerá tão inviável, quanto se faz pensar atualmente.

Em nível de mudanças na seara trabalhista, conclui-se que é sim preciso estar atento às mudanças na dinâmica social do trabalho e às inovações tecnológicas. O Direito do Trabalho precisa se modernizar, mas para isso, não deve perder em sua essência o seu viés protetor e de equiparação de forças entre o capital e o trabalho.

Diz-se então da importância de um Direito do Trabalho sensível às necessidades da coletividade e que prime pela verdadeira autonomia das relações coletivas. Essa autonomia, como já comentado, precisa estar em consonância com os limites politicamente aceitáveis, não violando direitos humanos. Ao contrário, deve buscar sempre a efetivação dos objetivos dirigentes da nova ordem constitucional.

\section{REFERÊNCIAS}

ALMEIDA, Cleber Lúcio de. Redução e Expansão do Direito do Trabalho: por um direito do trabalho de segunda geração. Em: Direito Material e Processual do Trabalho: III Congresso Latino-americano de Direito Material e Processual do Trabalho. Coords.: TEODORO, Maria Cecília Máximo; VIANA, Márcio Túlio; ALMEIDA, Cleber Lúcio de; NOGUEIRA, Sabrina Colares. São Paulo: LTr, 2016, p. 41-50.

BARros, Alice Monteiro de. Curso de Direito do Trabalho, 5. ed. rev. e ampl. São Paulo: LTr, 2009. 
BAUMAN, Zygmunt. Modernidade Líquida. Tradução: Plínio Dentzien. Rio de Janeiro: Jorge Zahar Ed., 2001.

BRASIL. Consolidação das Leis do Trabalho: DECRETO-LEI N ${ }^{\circ}$. 5.452, DE $1^{\circ}$. DE MAIO DE 1943. Disponível em: http://www.planalto.gov.br/ccivil_03/decreto-lei/Del5452.htm. Acesso em: 12 mar. 2018.

BRASIL. Constituição da República Federativa do Brasil: de 5 de outubro de 1988. Disponível em: http://www.planalto.gov.br/ccivil_03/Constituicao/ Constituicao.htm. Acesso em: 12 mar. 2018.

BRASIL. DECRETO Nº. 591, DE 6 DE JULHO DE 1992. Trata dos Atos Internacionais. Pacto Internacional sobre Direitos Econômicos, Sociais e Culturais. Disponível em: http://www.planalto.gov.br/ccivil_03/decreto/1990-1994/ d0591.htm. Acesso em: 12 mar. 2018.

BRASIL. Tribunal Regional do Trabalho da 23a Região. Ação anulatória 00160.2004.000.23.00-5. Relator: Paulo Brescovici. Diário de Justiça Eletrônico, Cuiabá-MT, 23 set. 2005. Disponível em: <http://www.trt23.jus.br/ acordao/2005/DJ7225/105033325.pdf. Acesso em: 4 mai. 2018.

CANOTILHO, José Joaquim Gomes. Direito Constitucional e Teoria da Constituição, 4. ed. Coimbra: Livraria Almedina, 2000.

CHAVES, D. C. P.; FERREIRA, C. C.; DANTAS, M. C. C. Reconhecimento e Trabalho: a aplicação da teoria de Axel Honneth no âmbito laboral. Estudos Contemporâneos em Direito Público e Privado, 1. ed. Belo Horizonte: D’Plácido, 2015, v. 1, p. 81-102.

CHIARELLI, Carlos Alberto. O trabalho e o sindicato: evolução e desafios. São Paulo: Ltr, 2005.

CISNEROS, Manuel Alejandro Ibarra; TORRES, Lourdes Alicia González. La flexibilidad laboral como estrategia de competitividad y sus efectos sobre laeconomía, la empresa y el mercado de trabajo, 2009.

DELGADO, Mauricio Godinho. Capitalismo, trabalho e emprego: entre o paradigma da destruição e os caminhos de reconstrução. São Paulo: LTr. 2005.

DELGADO, Mauricio Godinho. Curso de Direito do Trabalho, 13. ed. São Paulo: LTr. 2014. 
FRASER, Nancy; HONNETH, Axel. ¿Redistribución o reconocimiento? Um debate político-filosófico. Traduccíon de Pablo Manzano. Madrid: Ediciones Morata, S.L, 2006.

FREYSSINET, Jacques. As trajetórias nacionais rumo à flexibilidade da relação salarial: A experiência europeia. Obra coletiva: Trabalho flexível, empregos precários? Org.: Nadya Guimarães, Helena Hirata e Kurumi Sugita. Editora da USP, 2009.

HAZAN, Bruno Ferraz. A aderência contratual das normas coletivas. São Paulo: Ltr, 2012.

HONNETH, Axel. A Luta Por Reconhecimento: A gramática moral dos conflitos sociais. Tradução de Luiz Repa. São Paulo: Ed. 34, 2003.

HONNETH, Axel. FRASER, Nancy. Redistribution or Recognition?A political-philosophical exchange. London: Verso, 2003. HONNETH, Axel (Orgs.). Kommunitarismus: Eine Debatteüber diemoralischen Grundlagenmoderner Gesellschaften. Frankfurt am Main. New York: Campus, 2003.

LATAS, Ana Guerreiro; LIMA, Marinús Pires de Lima; NUNES, Cristina. Boas práticas laborais e negociação coletiva na Autoeuropa e sata-snpvac. Disponível em: http://analisesocial.ics.ul.pt/documentos/1332346829I2iNH6g x5Ge81RK5.pdf. Acesso em: 20 nov. 2017.

MARRAS, Jean Pierre. Relações trabalhistas no Brasil: administração e estratégia. São Paulo: Futura, 2001.

MASSONI, Túlio de Oliveira. Representatividade Sindical. São Paulo: Ltr, 2007.

MUÑOZ, Francisco Andrés Valle. Una Revisión Critica Al Discurso de la Flexibilidad em el Derecho del Trabajo. BOLETÍN DE LA FACULTAD DE DERECHO, n. 27, 2005.

NASCIMENTO, Amauri Mascaro. Compêndio de direito sindical, 2. ed. São Paulo: LTr, 2000.

NOGUEIRA, Lilian Katiusca Melo. Sindicalismo e Direitos Humanos: Para além da "Libertà Complessa". Em: Trabalho e Movimentos Sociais. Coords.: HENRIQUE, Carlos Augusto Junqueira; DELGADO, Gabriela Neves; VIANA, Márcio Túlio; RIBEIRO, Patrícia Henrique. Belo Horizonte: Del Rey, 2008, p. 132-146. 
ORGANIZAÇÃO INTERNACIONAL DO TRABALHO (OIT). Convenção n$^{0}$. 98. Disponível em: http://www.oitbrasil.org.br/node/465. Acesso em: 3 mai. 2018.

PASTORE, José. Flexibilização dos mercados de trabalho e contratação coletiva. São Paulo: Editora LTr, 1995.

PASTORE, José. Relações de trabalho numa economia que se abre. Instituto Liberal de São Paulo, Ideias Liberais, a. II. N27, 1995.

PEREIRA, João Batista Brito. O sindicalismo no Brasil. Uma proposta para o seu fortalecimento. Em: Direito coletivo do trabalho em uma sociedade pós-industrial. VIDORRI, Tárcio José; GIORDANI, Francisco Alberto da Motta Peixoto, coordenadores. São Paulo: LTR, 2003.

PINHEIRO, Maria Cláudia Bucchianeri. A Constituição de Weimar e os direitos fundamentais sociais. 2006. Disponível em: http://www2.senado.leg. br/bdsf/bitstream/handle/id/92449/Pinheiro\%20Maria.pdf?sequence=2. Acesso em: 22 abr. 2018.

SARLET. Ingo Wolfgang. A Eficácia dos Direitos Fundamentais: uma teoria geral dos direitos fundamentais na perspectiva constitucional, 10. ed. Porto Alegre: Livraria do Advogado, 2009.

SOUTO MAIOR, Jorge Luiz. História do direito do trabalho no Brasil: curso de direito do trabalho, volume: I: parte II. São Paulo: LTr, 2017.

STRECK, Lenio Luiz; MORAIS, José Luiz Bolzan de. Ciência política e teoria geral do estado. Porto Alegre, RS: Livraria do Advogado, 2000.

SUSSEKIND, Arnaldo. Arnaldo Sussekind, um apaixonado pelo Direito do Trabalho. Revista JC, 2007. Entrevista concedida a Giselle Souza. Disponível em: http:/www.editorajc.com.br/2007/08/arnaldo-sussekind-um-apaixonado-pelo-direito-do-trabalho/. Acesso em: 22 abr. 2018.

TEODORO, Maria Cecília Máximo. A síndrome de patrão. Palestra proferida no IV Congresso Latino-americano de Direito Material e Processual do Trabalho. Punta Del Leste/Uruguai, dez. 2015.

TEODORO, Maria Cecília Máximo. Capitalismo, trabalho e educação em tempos de neoliberalismo: diagnóstico e críticas. 2012. Disponível em: 
http://www.publicadireito.com.br/artigos/?cod=6ef80bb237adf4b6. Acesso em: 18 nov. 2015.

TEODORO, Maria Cecília Máximo. O princípio da Adequação Setorial Negociada no Direito do Trabalho. São Paulo: Editora LTr, 2007.

TEODORO, Maria Cecília Máximo. O princípio da adequação setorial negociada: limites e fortalecimento da negociação coletiva, 2013. Disponível em: http://livros-e-revistas.vlex.com.br/vid/pio-setorial-negociada-fortalecimento-503503058. Acesso em: 22 abr. 2018.

TEODORO, Maria Cecília Máximo; MIRAGLIA, Lívia Mendes Moreira. A relação de emprego contra-ataca a informalidade: Vantagens para os trabalhadores, para o estado e para a sociedade. Trabalho publicado nos Anais do XX Encontro Nacional do CONPEDI realizado em Belo Horizonte-MG, 2011.

TEODORO, Maria Cecília Máximo; VALADÃO, Carla Cirino. A flexibilização positiva: uma forma de tutelar e promover a dignidade humana do trabalhador. Em: Direito do Trabalho e seguridade social [Recurso eletrônico on-line] organização CONPEDI/UFS; Coordenadores: Luciana Aboim Machado Gonçalves da Silva, Mirta Gladys Lerena Manzo De Misailidis, Maria Aurea Baroni Cecato. Florianópolis: CONPEDI, 2015.

URIARTE, Orcar Ermida. A Flexibilidade. Tradução: Edilson Alkmim Cunha. São Paulo: Editora: LTr, 2002.

VIANA, Márcio Túlio. A Proteção Social do Trabalhador no Mundo Globalizado. In: PIMENTA, José Roberto Freire et al. (Coords.). Direito do Trabalho: Evolução, Crise, Perspectivas. São Paulo: LTr, 2004.

VIANA, Márcio Túlio. Da greve ao boicote: os vários significados e as novas possibilidades das lutas operárias. Em: Trabalho e Movimentos Sociais. Coords.: HENRIQUE, Carlos Augusto Junqueira; DELGADO, Gabriela Neves; VIANA, Márcio Túlio; RIBEIRO, Patrícia Henrique. Belo Horizonte: Del Rey, 2008, p. 105-130.

VIANA, Márcio Tulio. O sindicato e a proteção ao emprego. Em: Direito Coletivo do Trabalho em uma Sociedade Pós-Industrial. Coords.: VIDOTTI, Tárcio José; GIORDANI, Francisco Alberto da Motta Peixoto. São Paulo: Ltr, 2003. 
VIÑA, Jordi Garcia. Derecho Sindical: cuestiones actuales em Espanã. Lisboa: Editorial Juruá, 2013.

SOBRE O AUTOR

Marcos Paulo da Silva Oliveira

Mestrando em Direito do Trabalho pela Pontifícia Universidade Católica de Minas Gerais. Graduado em Direito pela Pontifícia Universidade Católica de Minas Gerais. Advogado. Pesquisador do Grupo de Pesquisa e Estudos em Direito do Trabalho RED - Retrabalhando o Direito, da Pontifícia Universidade Católica de Minas Gerais.

CV: http://lattes.cnpq.br/0616245708710928

Email: marcosbrumal@hotmail.com

Submetido em: 7-3-2017

Aceito em: 10-11-2017 